\title{
Application of the SWAP model to predict impact of climate change on soil water balance in a Sicilian vineyard
}

\author{
Giuseppina Crescimanno, ${ }^{1}$ Francesco Morga, ${ }^{1}$ Domenico Ventrella² \\ ${ }^{1}$ Dipartimento dei Sistemi Agro-Ambientali, Università di Palermo; ${ }^{2}$ Consiglio per la Ricerca e la \\ sperimentazione in Agricoltura - Unità di ricerca per i Sistemi Colturali degli Ambienti caldo-aridi \\ (CRA-SCA), Bari, Italy
}

\begin{abstract}
In Sicily, the increasing scarcity of quality water is leading to irrigation with saline water in soils having a considerable susceptibility to salinization and degradation. In this paper, water flow and solute transport in a Sicilian irrigated soil was simulated by using the SWAP model, and the simulated results compared to measured values of soil moisture and salinity. The investigation was carried out in a vineyard located in Sicily (Mazara del Vallo, Trapani) within the framework of the Project Evolution of cropping systems as affected by climate change (CLIMESC0). The soil hydraulic parameters were obtained by inverse method based on multi-step outflow experiments. The results obtained using field measurements from two soil profiles showed that SWAP provided reliable predictions of water content, $\theta$, and of electrical conductivity of saturated extract, $E C_{\text {sat }}$. The effect of climate change on soil water balance was predicted by application of SWAP under the soilcrop and irrigation management conditions currently practiced in the vineyard. Simulations were carried out with climatic data generated by the statistical downscaling process based on the global CGM HADCM3 for two IPCC scenarios (A2 and B1) and for the 2070-2100 time interval. The two mentioned IPCC scenarios (A2 and B1) were then compared to a third reference scenario (BASELINE) obtained by using the
\end{abstract}

Correspondence: Prof. Dr. Giuseppina Crescimanno, Università di Palermo, Dipartimento dei Sistemi Agro-Ambientali, viale delle Scienze 13, 90128 Palermo, Italy. Tel. +39.091 .23862201 - Fax: +39.091 .484035 .

E-mail: giuseppe.crescimanno@unipa.it

Key words: grapes, water balance, climate change, adaptation strategies.

Acknowledgements: this research was funded by CLIMESCO Evolution of cropping systems as affected by climate change project, contract n. 285, 20/02/2006 (Ministry for Education, University and Research).

Received for publication: 23 May 2011.

Accepted for publication: 2 November 2011.

(C) Copyright G. Crescimanno et al., 2012

Licensee PAGEPress, Italy

Italian Journal of Agronomy 2012; 7:e17

doi:10.4081/ija.2012.e17

This article is distributed under the terms of the Creative Commons Attribution Noncommercial License (by-nc 3.0) which permits any noncommercial use, distribution, and reproduction in any medium, provided the original author(s) and source are credited. climatic data recorded from 1951 to 2004 . The results indicated that the only significant effect of climate change was to shorten and to advance the crop cycle length, which decreased of 16 and 27 days respectively in $\mathrm{B} 1$ and $\mathrm{A} 2$ compared to values obtained for the BASELINE scenario. Further application of SWAP carried out simulating an advance in the irrigation starting time according to the advance in the crop cycle indicated that this could be considered a kind of adaptation strategy to be applied in the future in the vineyard to counterbalance the impact of climate change. This means that in the future farmers might be likely to anticipate the irrigation season in order to avoid any significant reduction in the crop productivity.

\section{Introduction}

Application of physically-based models simulating water and solute transport, and predicting soil salinity (expressed by measurement of electrical conductivity or by concentration of the pore solution), represents an essential tool for the development of management scenarios suitable to prevent salinization. By these models different options can be analysed and compared, and strategies for sustainable irrigation in the short and in the long term can be delineated (Crescimanno and Garofalo, 2006). Van Dam et al. (1997) developed a model for fine-textured clay soils containing shrinkage cracks. This model, named SWAP93, takes into account shrinking and swelling as a function of the water content, and uses statistical properties of cracks as parameter input. SWAP93 provides as output the water content (and matric potential), as well as the concentration of the soil solution, $\mathrm{C}$, from which the electrical conductivity of the saturated extract $\left(E C_{\text {sat }}\right)$ can be also calculated (Rhoades, 1996). With reference to solute transport, SWAP93 predicts solute concentration (C) by using the advection-dispersion (ADE) equation, assuming a constant dispersivity and neglecting the process of cationic exchange. Due to these simplifying assumptions, accuracy of the predicted $\mathrm{C}$ or $E C_{\text {sat }}$ in clay soil needs to be checked by comparison with measured $E C_{\text {sat }}$ values.

Climate change is already happening and represents one of the greatest environmental, social and economic threats facing the planet. The warming of the climate system is unequivocal, as is now evident from observations of increases in global average air and ocean temperatures, widespread melting of snow and ice, and rising global mean sea level. Global climate change may have serious impacts on water resources and agriculture in the future. Based on a range of several current climate models, the mean annual global surface temperature is projected to increase by 1.4 to $5.8^{\circ} \mathrm{C}$ over the period of 1990 to 2100 (IPCC, 2007), with changes in the spatial and temporal patterns of precipitation (Southworth et al., 2000). Semi-arid areas already suffering from limited water availability are likely to be most sensitive to climate 
change due to an increase in water demand for irrigation projected under a warmer climate. It is therefore necessary to develop adaptation strategies aimed at counterbalancing the adverse impact of climate change. This paper reports results of a field investigation carried out in a vineyard located in Sicily (Mazara del Vallo, Trapani Province) within the framework of the project Evolution of cropping systems as affected by climate change (CLIMESCO), funded by three Italian Ministries (University, Agriculture, and Environment). Investigation was carried out at the Foraci Farm (http://www.cantineforaci.com/), a vineyard located in the Mazaro basin region of Sicily, where two different irrigation treatments were established ( $\mathrm{L}$ and $\mathrm{R}$ ) to monitor soil response to irrigation water salinity (Crescimanno and Marcum, 2009). The first objective of this investigation was to evaluate the ability of SWAP to accurately predict both $\theta$ and $E C_{\text {sat }}$ in two soil profiles located in the $\mathrm{L}$ and $\mathrm{R}$ plots respectively. The second objective was to evaluate the impact of climate change on soil water balance, crop water stress and irrigation strategies in the Foraci vineyard.

\section{Materials and methods}

Data collection was carried out in a vineyard located in the Mazaro basin region of western Sicily (Foraci Farm, Trapani), (37 $40^{\circ} 55^{\prime \prime} \mathrm{N}$; $12^{\circ} 38^{\prime} 50$ " E). Soil was uniform across the research area, classified as Typic Calcicxerept (Soil Survey Staff, 1999) with soil texture a clay according to USDA classification). The research area was divided into two large $\left(2300 \mathrm{~m}^{2}\right)$ irrigation sections (Figure 1), each receiving a different irrigation water source. Irrigation treatment $L$ used irrigation water from a lake having $E C=1.6 \mathrm{dS} \mathrm{m}^{-1}$, irrigation treatment $R$ used water from a well having $\mathrm{EC}=0.6 \mathrm{dS} \mathrm{m} \mathrm{m}^{-1}$. Two soil profiles were selected in the $L$ and $R$ treatments respectively, named Foraci_G (L treatment) and Foraci_F (R treatment).

Table 1 reports the soil physical characteristics, together with the soil classification (Soil Survey Staff, 1999) for the two considered soil profiles. Undisturbed soil cores (diameter $d=8.5 \mathrm{~cm}$, height $H=11.5$ $\mathrm{cm})$ were sampled to measure the soil shrinkage curve, which was determined by measuring vertical and horizontal shrinkage (Crescimanno and Provenzano, 1999). Replicated soil cores ( $d=8.5 \mathrm{~cm}$, $H=5 \mathrm{~cm}$ ) were sampled to determine soil hydraulic parameters/functions by inverse method based on multi-step (MSTEP) outflow experiments. The MSTEP experiments were performed in pressure cells by applying three successive steps with pneumatic pressures ranging from 10 to $40 \mathrm{~cm}$, from 40 to $70 \mathrm{~cm}$, and from 70 to $800 \mathrm{~cm}$ (Crescimanno and Garofalo, 2005). After the MSTEP experiments, the cores were put in a pressure plate apparatus in order to measure the water content at $\mathrm{h}=-15300 \mathrm{~cm}$, i.e. wilting point, $\theta_{w p}$. Independent measurement of $\theta_{s}$ and $\theta_{w p}$ was necessary because only the pressure range from 10 to about $1000 \mathrm{~cm}$ can be explored in the pressure cells used for the MSTEP. Parameter estimation was carried out according to Crescimanno and Garofalo (2005), representing the soil hydraulic functions by:

the equation proposed by Brutsaert (B) (1966), for the water retention curve:

$$
\frac{\theta-\theta_{r}}{\theta_{s}-\theta_{r}}=\Theta=\left[1+\left|\alpha^{\prime} h\right|^{n^{\prime}}\right]^{-1}
$$

coupled with the model proposed by Gardner (G) (Gardner, 1958) for the hydraulic conductivity function $k(h)$ :

$$
k(h)=\frac{k_{s a t}}{1+|\beta h|^{\lambda}}
$$

Parameter estimation was performed by fixing both the saturated water content and the saturated hydraulic conductivity, $K_{s}$, at the measured values. Optimized parameters of the B-G model were therefore $\theta_{r}$, $\alpha^{\prime}, \lambda^{\prime}$ and $n^{\prime}$ (eqs. 1 and 2).

Irrigation scheduling was established according to a water balance model taking into account climatic data, the amount of soil water available for crops $\left(\mathrm{AW}_{\mathrm{max}}\right)$, and crop parameters. Table 2 reports the irrigation scheduling applied from 7 June 2007 to 30 July 2009. Irrigation in $\mathrm{R}$ and $\mathrm{L}$ row plots was performed on subsequent days.

Simulations were carried out with SWAP using March $1^{\text {st }} 2007$ as starting date for the vegetative growth and September $15^{\text {th }}$ as the max-

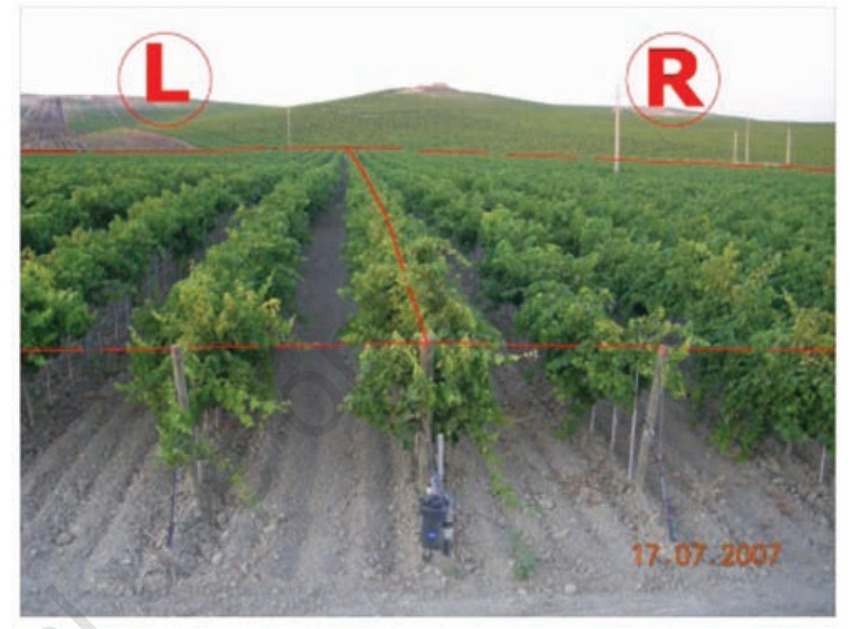

Figure 1. Foraci Farm (Mazaro basin, Sicily, Italy): location of the two treatments ( $L$ and $R)$.

Table 1. Physical characteristics and soil classification (Soil Survey Staff, 1999) of the two soil profiles.

\begin{tabular}{lllcccc} 
Soil Classification Horizon & $\begin{array}{c}\text { Depth } \\
(\mathrm{cm})\end{array}$ & $\begin{array}{c}\text { Clay } \\
(\%)\end{array}$ & $\begin{array}{c}\text { Silt } \\
(\%)\end{array}$ & $\begin{array}{c}\text { Sand } \\
(\%)\end{array}$ \\
Foraci_F & Typic Calcixerepts & Akp1 & $0-30$ & 47 & 42 & 11 \\
Foraci_F & Typic Calcixerepts & Akp2 & $30-60$ & 54 & 36 & 10 \\
\hline Foraci_G & Typic Calcixerepts & Akp1 & $0-20$ & 53 & 37 & 9 \\
Foraci_G & Typic Calcixerepts & Akp2 & $20-60$ & 52 & 37 & 11 \\
\hline
\end{tabular}

Table 2. Irrigation scheduling and measurement dates from 2007

\begin{tabular}{|c|c|c|c|}
\hline \multicolumn{2}{|c|}{ L treatment } & \multicolumn{2}{|c|}{$\mathbf{R}$ treatment } \\
\hline Irrigation & Measurements & Irrigation & Measurements \\
\hline 7 June 2007 & - & 7 June 2007 & - \\
\hline 17 July 2007 & 18 July 2007 & 18 July 2007 & 19 July 2007 \\
\hline 25 July 2007 & 26 July 2007 & 26 July 2007 & 27 July 2007 \\
\hline 25 June 2008 & 26 June 2008 & 24 June 2008 & 25 June 2008 \\
\hline 1st July 2008 & 2 July 2008 & 30 June 2008 & $1^{\text {st July } 2008}$ \\
\hline 8 July 2008 & 9 July 2008 & 7 July 2008 & 8 July 2008 \\
\hline 16 July 2008 & 17 July 2008 & 15 July 2008 & 16 July 2008 \\
\hline 29 July 2008 & 30 July 2008 & 28 July 2008 & 29 July 2008 \\
\hline 8 July 2009 & 9 July 2009 & 7 July 2009 & 8 July 2009 \\
\hline 22 July 2009 & 23 July 2009 & 21 July 2009 & 22 July 2009 \\
\hline 30 July 2009 & 31 July 2009 & 29 July 2009 & 30 July 2009 \\
\hline
\end{tabular}
to 2009. 
imum harvest date. According to the on-going irrigation practices aimed at improving wine quality in the Foraci vineyard irrigation scheduling was simulated in a limited time interval, ranging from July $1^{\text {st }}$ to July $31^{\text {st }}$. This is the current irrigation practice adopted by the farmers to achieve a controlled crop water stress from the end of July until harvesting.

Irrigation (Ir) was scheduled by SWAP after adopting a fraction equal to 0.9 for the allowable depletion of the totally available water (TAW). Irrigation depth was calculated by using a fraction of the TAW equal to 0.45 . Crop phenology was simulated by adopting a variable crop cycle based on the sum of temperatures recorded from the vegetative growth to anthesis, and then from anthesis to maturity $\left(920\right.$ and $2500^{\circ} \mathrm{C}$, respectively). A soil cover fraction of 0.5 was used to partition the reference evapotranspiration (ETo) into potential evaporation and transpiration. A root depth of $1 \mathrm{~m}$ was assumed, with a linearly decreasing root density distribution from top to bottom. Crop water uptake was calculated adopting the values of $-1000 \mathrm{~cm}$ and of $-16,000 \mathrm{~cm}$ for HLIM3 and for HLIM4 parameters (van Dam et al., 1992). Gravimetric water content $(U)$ was determined on undisturbed soil cores sampled at 15 , 30 and $60 \mathrm{~cm}$ in the two profiles on several dates from 21 June 2007 to 19 October 2008. Bulk density $\left(\rho_{b}\right)$ was determined from the measured shrinkage curve; $U$ and $\rho_{b}(U)$ were used to calculate volumetric water content, $\theta$. Soil saturated extracts were prepared using the soil collected in the field. Soil electrical conductivity, $E C_{\text {sat }}$, was determined on these extracts by a conductivimeter (Micro CM 2002, Crison Strumenti, Carpi, M0, Italy).

To check accuracy of predicted $\theta$, the root mean squared residual $\left(R M S R_{\theta}\right)$ between measured and predicted $\theta$ values was calculated as:

$$
\operatorname{RMSR}_{\theta}=\sqrt{\frac{\sum_{i=1}^{N}\left(\theta_{\text {meas }}-\theta_{\text {pred }}\right)^{2}}{N}}
$$

where $\theta_{\text {pred }}$ is the predicted value, $\theta_{\text {meas }}$ is the measured value, and $N$ is the number of measurements. To check systematic errors between measured and predicted $\theta$, predicted values were regressed against the measured values, and hypotheses that the slope $(b)$ of the regression line was not significantly different from 1 , and that the intercept $(a)$ of the regression line was not significantly different from 0 , were checked. The Durbin-Watson $(D W)$ test was used to check whether the random errors in the regression line exhibited autocorrelation (Crescimanno and Garofalo, 2005).

The d-index (d) (Willmott, 1981) was also calculated (Ali et al., 2000):

$$
d=1-\frac{\sum_{i=1}^{n}\left(P_{i}-O_{i}\right)^{2}}{\sum_{i=1}^{n}\left(\left|P_{i}^{\prime}\right|-\left|O_{i}^{\prime}\right|\right)^{2}}
$$

where $P_{i}$ and $O_{i}$ are the predicted and observed concentrations (at a particular depth and time), respectively, and $O_{m}$ is the average of all observed values. The denominator quantities are computed as $P_{i}{ }_{i}=P_{i^{-}}$ $O_{m}$ and $O_{i}^{\prime}=O_{i}-O_{m}$ respectively. According to Willmott (eq. 4), a $d$ value equal to 1 indicates perfect agreement between predicted and observed values, and a $d$ value of 0 indicates perfect non-agreement. Between these two extremes, there are no statistically derived thresholds of acceptable agreement. The dimensionless $d$ is a measure of model efficiency because i) it takes into account additive differences or differences in proportionality which are not taken into account by the correlation coefficient $(R)$; and ii) it is sensitive to differences between observed and estimated means (Willmott, 1981). For our system we assumed a $d$ value of 0.6 as the threshold value discriminating an acceptable prediction from an unsatisfactory result. For the two soils, $d$ values were calculated with reference to single depths ( $d$ values at 15 , 30,60 and $80 \mathrm{~cm}$ ) to check reliability of predicted $\theta$ and $E C_{\text {sat }}$.

After checking accuracy of the predicted $\theta$ and $E C_{\text {sat }}$, the effect of climate change simulated by Pizzigalli $e t$ al. (2012) on soil water balance was predicted by application of SWAP under the soil-crop and irrigation management conditions currently practiced in the Foraci vineyard. Specifically, SWAP was applied using climatic data generated by the statistical downscaling process based on the global CGM HADCM3 for two IPCC scenarios (A2 and B1) and for the 2070-2100 time interval. The two mentioned IPCC scenarios (A2 and B1) were then compared to a third reference Baseline scenario (BASELINE) obtained by using the climatic data recorded from 1951 to 2004 . The climatic parameters used were: daily minimum temperature, maximum temperature, global radiation, and rainfall. The Priestly-Taylor equation (Priestly-Taylor, 1972) was used to estimate the reference evapotranspiration (ETo).

The crop water stress index (CWSI), the irrigation efficiency (IE) and the ratio (Er) between actual evaporation (Ea) and actual evapotranspiration (Eta) were calculated by the following equations:

$$
\begin{gathered}
C W S I=1-\frac{T_{a}}{T_{p}} \\
I E=\frac{E_{a}}{I r} \\
E r=\frac{E_{a}}{E T_{a}}
\end{gathered}
$$

CWSI is considered an index related to crop productivity especially in arid areas (Doorenbos and Kassam (1979).

\section{Results and discussion}

Figure 2 shows the temporal evolution of the most important climatic parameters at the monthly scale, i.e.: minimum and maximum temperatures, rainfall and reference evapotranspiration (ETo) calculated by the Priestly-Taylor equation.

For both the two future IPCC scenarios, the GCM HADCM3 showed a significant increase in the minimum and in the maximum temperature from April to December compared to the values obtained for the BASELINE. The increase was more evident for the A2 scenario, for which the average monthly maximum temperature values exceeded $35^{\circ} \mathrm{C}$ from June to September, being $6^{\circ} \mathrm{C}$ higher than those found in the BASELINE. The minimum temperatures approximately showed the same increase. The highest increase in the minimum and maximum temperatures was found from May to September. As expected, the increase in the minimum and maximum temperature was less significant in the B1 scenario than in A2: the average monthly maximum temperatures values of $\mathrm{B} 1$ exceeded the value of $30^{\circ} \mathrm{C}$. The thermal variations compared to the BASELINE were significantly lower in the winter period than during the spring and the summer seasons.

With reference to rainfall, the $\mathrm{A} 2$ and $\mathrm{B} 1$ scenarios showed almost the same annual rainfall of about $545 \mathrm{~mm}$. This value was not significantly different from that of the BASELINE (534 mm). Considering the 
rainfall at the monthly scale, the same temporal pattern of the BASELINE was obtained for the $\mathrm{A} 2$ and $\mathrm{B} 1$ scenarios, with the rainfall concentrated in the winter and in autumn and with an arid period with almost no rainfall characterizing the summer season. The differences between the A2 and B1 scenarios and the BASELINE mainly occurred in autumn, and showed an increase. Figure 1 also reports the daily Eto averaged at monthly scale. The A2 and B1 scenarios showed the same temporal evolution of the BASELINE, except for the two first winter months. A significant increase in Eto was found for the A2 and B1 scenarios compared to the BASELINE from April to December, with a monthly increase ranging from $5 \%$ to $19 \%$ in $\mathrm{B} 1$ and from 8 to and $33 \%$ in A2. The soil hydraulic parameters determined for the two soils are reportd in Table 3, while Table 4 reports some information related to the simulations performed using the SWAP model. Table 5 reports values of the parameters determined to check accuracy of the predicted $\theta$, which values were in close agreement with those measured for the two soil profiles. The $a$ and $b$ parameters of the equation found by regressing the predicted $\theta$ against those measured were not significantly different from 0 and 1 respectively at the 0.01 probability level except for two of the considered cases. This indicated a satisfactory match between measured and predicted $\theta$. The $\mathrm{d}$ values were all higher than 0.65 , with values ranging between 0.68 (one case only) and 0.88 . These results confirmed that the $B-G$ parameters/functions accurately represented the hydraulic behavior of the considered soil. Since no calibration was performed to adjust the estimated hydraulic properties, the good match between the measured and the simulated $\theta$, obtained using the $B$ - $G$ soil hydraulic properties, also confirmed previous results (Crescimanno and Garofalo, 2005).

Figure 3 illustrates the agreement between the measured and the simulated $\theta$ for the two soil profiles at the depth of 30 and $60 \mathrm{~cm}$. Table 6 reports values of the parameters determined to check accuracy of the predicted $E C_{\text {sat }}$. Prediction of $E C_{\text {sat }}$ was less accurate than prediction of water content, $\theta$, with RMSRECsat ranging from a minimum of 0.312 to a maximum of $0.624 \mathrm{dS} \mathrm{m}^{-1}$. However, the $a$ and $b$ parameters of the equation found by regressing the predicted values against those measured were not significantly different from 0 and 1 respectively at the 0.01 probability level except for three of the considered cases. The $d$ values ranged from a minimum of 0.65 to a maximum of 0.93 , indicating reliable prediction. Accuracy of the predicted $E C_{\text {sat }}$ was therefore considered acceptable and comparable with the predictive accuracy of SWAP previously investigated with reference to other Sicilian soil profiles (Crescimanno and Garofalo, 2005; 2006).

Figure 4 illustrates the simulated and the measured $E C_{\text {sat }}$ for the two profiles at the depths of 30 and $60 \mathrm{~cm}$. With reference to the impact of
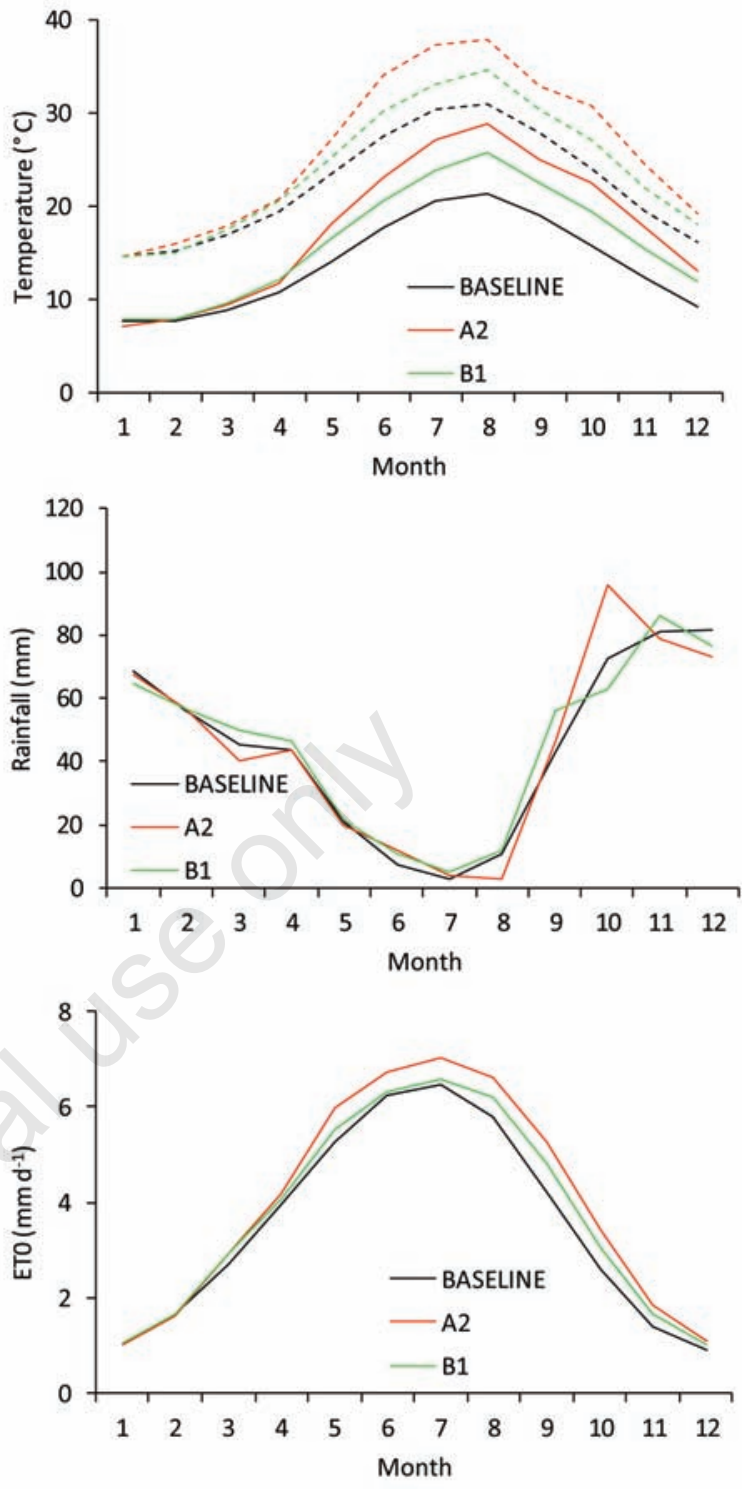

Figure 2. Effect of climate change on monthly temperature (continuous and dashed lines for minimum and maximum temperature, respectively), rainfall and reference evapotranspiration (ETo).

Table 3. Soil hydraulic parameters (B-G model).

\begin{tabular}{|c|c|c|c|c|c|c|c|c|c|}
\hline Soil & $\begin{array}{c}\text { Depth } \\
\mathrm{cm}\end{array}$ & $\begin{array}{c}K_{s} \\
\mathrm{~cm} \mathrm{~h}^{-1}\end{array}$ & Os & $\mathrm{cm}^{3} \mathrm{~cm}^{-3}$ & $\begin{array}{c}\theta r \\
\mathrm{~cm}^{-1}\end{array}$ & $\alpha^{\circ}$ & $\begin{array}{l}n^{\circ} \\
-\end{array}$ & $\beta^{\circ}$ & $\lambda^{\circ}$ \\
\hline Foraci_F & $0-30$ & 3.62 & 0.45 & & 0.26 & 0.005 & 0.379 & 2.184 & 1.725 \\
\hline Foraci_G & $0-20$ & 1.94 & 0.45 & & 0.25 & 0.005 & 0.533 & 1.337 & 2.472 \\
\hline Foraci_G & $20-60$ & 1.44 & 0.45 & & 0.25 & 0.001 & 0.363 & 1.169 & 2.554 \\
\hline
\end{tabular}

$K_{s}$, saturated hydraulic conductivity of the soil matrix (measured value); $\theta_{s}$, saturated volumetric water content at saturation (measured value); $\theta_{\xi}$, residual water content (optimized value); ${ }^{\circ}$ parameters of B-G model.

Table 4. Data related to the simulations performed using SWAP.

\begin{tabular}{lccccccc} 
Soil & Simulation period & $\begin{array}{c}\text { Lenght of simulation } \\
\text { (days) }\end{array}$ & $\begin{array}{c}\text { Total rainfall } \\
(\mathrm{mm})\end{array}$ & $\begin{array}{c}\text { Number of irrigations } \\
-\end{array}$ & $\begin{array}{c}\text { Total irrigation } \\
(\mathrm{mm})\end{array}$ & $\begin{array}{c}\text { EC } \\
\left(\mathrm{dS} \mathbf{m}^{-1}\right)\end{array}$ & $\begin{array}{c}\text { SAR } \\
-\end{array}$ \\
Foraci_F & $28 / 06 / 2007-01 / 09 / 2009$ & 796 & 1517 & 13 & 486 & 0.60 & 3.20 \\
Foraci_G & $28 / 06 / 2007-01 / 09 / 2009$ & 796 & 1517 & 13 & 486 & 1.60 & 6.07 \\
\hline
\end{tabular}

EC, electrical conductivity of water used to irrigate the two profiles; SAR, sodium adsorption ratio of water used to irrigate the two profiles. 
Table 5. Values of the parameters determined to check accuracy of the predicted $\theta$.

\begin{tabular}{|c|c|c|c|c|c|c|c|c|}
\hline \multirow[b]{2}{*}{ Depth (cm) } & \multicolumn{4}{|c|}{ Foraci F } & \multicolumn{4}{|c|}{ Foraci G } \\
\hline & 15 & 30 & 60 & 80 & 15 & 30 & 60 & 80 \\
\hline $\mathrm{N}$ & 46 & 46 & 46 & 46 & 46 & 46 & 46 & 46 \\
\hline $\operatorname{RMSE}_{\theta},\left(\mathrm{m}^{3} \mathrm{~m}^{-3}\right)$ & 0.042 & 0.037 & 0.043 & 0.035 & 0.051 & 0.034 & 0.037 & 0.053 \\
\hline $\mathrm{b}$ & $0.72^{*}$ & 0.69 & $0.69^{*}$ & $0.99 *$ & 0.57 & $0.72^{*}$ & $0.66^{*}$ & 0. \\
\hline $\mathrm{a}$ & 0.12 & 0.12 & 0.12 & $0^{*}$ & 0.17 & $0.1^{*}$ & $0.13^{*}$ & $0.07^{*}$ \\
\hline $\mathrm{R}$ & 0.63 & 0.80 & 0.71 & 0.78 & 0.68 & 0.73 & 0.65 & 0.50 \\
\hline$m_{\theta}\left(m^{3} m^{-3}\right)$ & 0.35 & 0.35 & 0.35 & 0.33 & 0.37 & 0.36 & 0.36 & 0.36 \\
\hline d-index & 0.78 & 0.88 & 0.80 & 0.88 & 0.80 & 0.85 & 0.80 & 0.68 \\
\hline DW test & $1.49 *$ & $1.38 *$ & $0.71^{*}$ & $1.26^{*}$ & $1.35^{*}$ & $1.43^{*}$ & $1.03^{*}$ & $1.31^{*}$ \\
\hline
\end{tabular}

$\mathrm{N}$, number of measurements; $\mathrm{RMSE}_{\theta}$, root mean squared residual; a, intercept of linear regression equation; $b$, slope of linear regression equation; $\mathrm{R}$, correlation coefficient; $\mathrm{m}$, average of measurements $\theta ; \mathrm{d}-$ index, index of agreement of Willmott (Willmott, 1981); DW, Durbin-Watson test. *Significance at the 0.01 probability level.

Table 6. Values of the parameters determined to assess accuracy of the predicted $E C_{\text {sat }}$.

\begin{tabular}{|c|c|c|c|c|c|c|c|c|}
\hline \multirow[b]{2}{*}{ Depth (cm) } & \multicolumn{4}{|c|}{ Foraci $\mathrm{F}$} & \multicolumn{4}{|c|}{ Foraci G } \\
\hline & 15 & 30 & 60 & 80 & 15 & 30 & 60 & 80 \\
\hline $\mathrm{N}$ & 46 & 46 & 46 & 46 & 46 & 46 & 46 & 46 \\
\hline $\operatorname{RMSE}_{\mathrm{ECsat}},\left(\mathrm{dS} \mathrm{m}^{-1}\right)$ & 0.312 & 0.325 & 0.383 & 0.544 & 0.624 & 0.573 & 0.601 & 0.314 \\
\hline $\mathrm{b}$ & $0.87^{*}$ & $0.78^{*}$ & $1.14^{*}$ & 2.22 & 0.39 & 0.63 & $0.84^{*}$ & $0.96^{*}$ \\
\hline $\mathrm{a}$ & 0.35 & $0.45^{*}$ & $-0.36^{*}$ & -2.72 & 0.95 & 0.82 & $0.56^{*}$ & $0.08 *$ \\
\hline $\mathrm{R} 2$ & 0.94 & 0.85 & 0.78 & 0.89 & 0.68 & 0.84 & 0.71 & 0.87 \\
\hline $\mathrm{m}_{\mathrm{ECsat}}\left(\mathrm{dS} \mathrm{m}^{-1}\right)$ & 1.39 & 1.50 & 1.73 & 1.95 & 1.37 & 1.63 & 1.76 & 1.67 \\
\hline d-index & 0.93 & 0.83 & 0.68 & 0.68 & 0.65 & 0.78 & 0.68 & 0.88 \\
\hline DW test & $0.78^{*}$ & $1.04^{*}$ & $1.07^{*}$ & $0.81^{*}$ & $0.51^{*}$ & $0.24^{*}$ & $0.25^{*}$ & $0.74^{*}$ \\
\hline
\end{tabular}

$\mathrm{N}$, number of measurements; $\mathrm{RMSE}_{\mathrm{EC} \text { sat, }}$, root mean squared residual; a, intercept of linear regression equation; b, slope of linear regression equation; R, correlation coefficient; $m_{E C \text { csat }}$, average of measurements $E C_{\text {sat }}$; d-index, index of agreement of Willmott (Willmott, 1981); DW, Durbin-Watson test. * Significance at the 0.01 probability level.

Table 7. Values of parameters obtained by simulating impact of climate change (climate change scenarios BASELINE, B1 and A2) using SWAP; values of the same parameters obtained by simulating impact of climate change advancing the irrigation season according to the shortening and advancing of the crop cycle length (scenarios B1-Ad and A2-AD).

\begin{tabular}{|c|c|c|c|c|c|c|c|c|c|c|c|}
\hline Scenario & $\begin{array}{l}\text { CL } \\
\text { (d) }\end{array}$ & $\mathbf{R}$ & Ir & $\mathrm{Tp}$ & $\begin{array}{c}\mathrm{Ta} \\
(\mathrm{mm})\end{array}$ & Ep & Ea & Qb & CWSI & $\begin{array}{l}\text { IE } \\
-\end{array}$ & Er \\
\hline \multicolumn{12}{|l|}{ Baseline } \\
\hline Mean & 187.63 & 135.90 & 149.63 & 521.03 & 345.89 & 521.03 & 142.74 & 97.24 & 0.31 & 2.31 & 0.29 \\
\hline SD & 8.19 & 55.01 & 1.70 & 21.26 & 42.74 & 21.26 & 25.15 & 81.43 & 0.17 & 0.29 & 0.03 \\
\hline VC & 4.37 & 40.48 & 1.13 & 4.08 & 12.36 & 4.08 & 17.62 & 83.75 & 54.83 & 12.73 & 8.83 \\
\hline \multicolumn{12}{|l|}{ B1 } \\
\hline Mean & 171.27 & 138.77 & 149.74 & 491.90 & 388.86 & 491.90 & 151.19 & 65.29 & 0.21 & 2.60 & 0.28 \\
\hline S. dev & 0.98 & 35.27 & 1.55 & 3.90 & 32.73 & 3.90 & 17.01 & 46.73 & 0.07 & 0.23 & 0.02 \\
\hline VC & 0.57 & 25.41 & 1.04 & 0.79 & 8.42 & 0.79 & 11.25 & 71.58 & 31.41 & 8.74 & 7.17 \\
\hline \multicolumn{12}{|l|}{$\mathrm{A} 2$} \\
\hline Mean & 161.00 & 120.16 & 150.34 & 481.29 & 383.09 & 481.29 & 142.69 & 78.07 & 0.19 & 2.55 & 0.27 \\
\hline SD & 1.02 & 35.24 & 2.29 & 5.13 & 44.27 & 5.13 & 19.01 & 45.14 & 0.12 & 0.31 & 0.02 \\
\hline VC & 0.63 & 29.33 & 1.53 & 1.07 & 11.56 & 1.07 & 13.32 & 57.82 & 65.25 & 12.04 & 9.04 \\
\hline \multicolumn{12}{|l|}{ B1-AD } \\
\hline Mean & 171.27 & 138.77 & 145.15 & 491.90 & 387.70 & 491.90 & 150.31 & 65.04 & 0.21 & 2.69 & 0.28 \\
\hline SD & 0.98 & 35.27 & 10.06 & 3.90 & 32.56 & 3.90 & 16.88 & 46.64 & 0.07 & 0.38 & 0.02 \\
\hline VC & 0.57 & 25.41 & 6.93 & 0.79 & 8.40 & 0.79 & 11.23 & 71.70 & 30.83 & 14.07 & 7.24 \\
\hline \multicolumn{12}{|l|}{ A2-AD } \\
\hline Mean & 161.00 & 120.16 & 144.89 & 481.28 & 378.88 & 481.28 & 140.08 & 75.38 & 0.21 & 2.64 & 0.27 \\
\hline S. dev & 1.02 & 35.24 & 9.32 & 5.13 & 44.04 & 5.13 & 19.57 & 44.36 & 0.09 & 0.47 & 0.03 \\
\hline $\mathrm{VC}$ & 0.63 & 29.33 & 6.43 & 1.07 & 11.62 & 1.07 & 13.97 & 58.85 & 42.72 & 17.76 & 9.57 \\
\hline
\end{tabular}


climate change on soil water balance, crop stress and irrigation requirement, Table 7 reports the main results obtained by the simulations. Figure 5 illustrates the temporal evolution of the CWSI for three representative years (2004 for the BASELINE, 2080 for B1 and A2) selected for each of the simulated scenarios (BASELINE, B1 and A2). As it can be seen in Figure 5, the CWSI values obtained for the BASELINE scenario tend to increase from 0 to 1 starting from the beginning of
March until the end of June, showing some variability due to rainfall events. CWSI suddenly decreases at the beginning of July in concomitance with starting of irrigation, ranges between 0.2 and 0.4 during July and then rapidly increases in August until reaching a constant value of about 1 after August 20. The CWSI values obtained by the B1 scenario show that water stress in grapes is higher and starts before compared to results provided by the BASELINE scenario. This effect can be attrib-
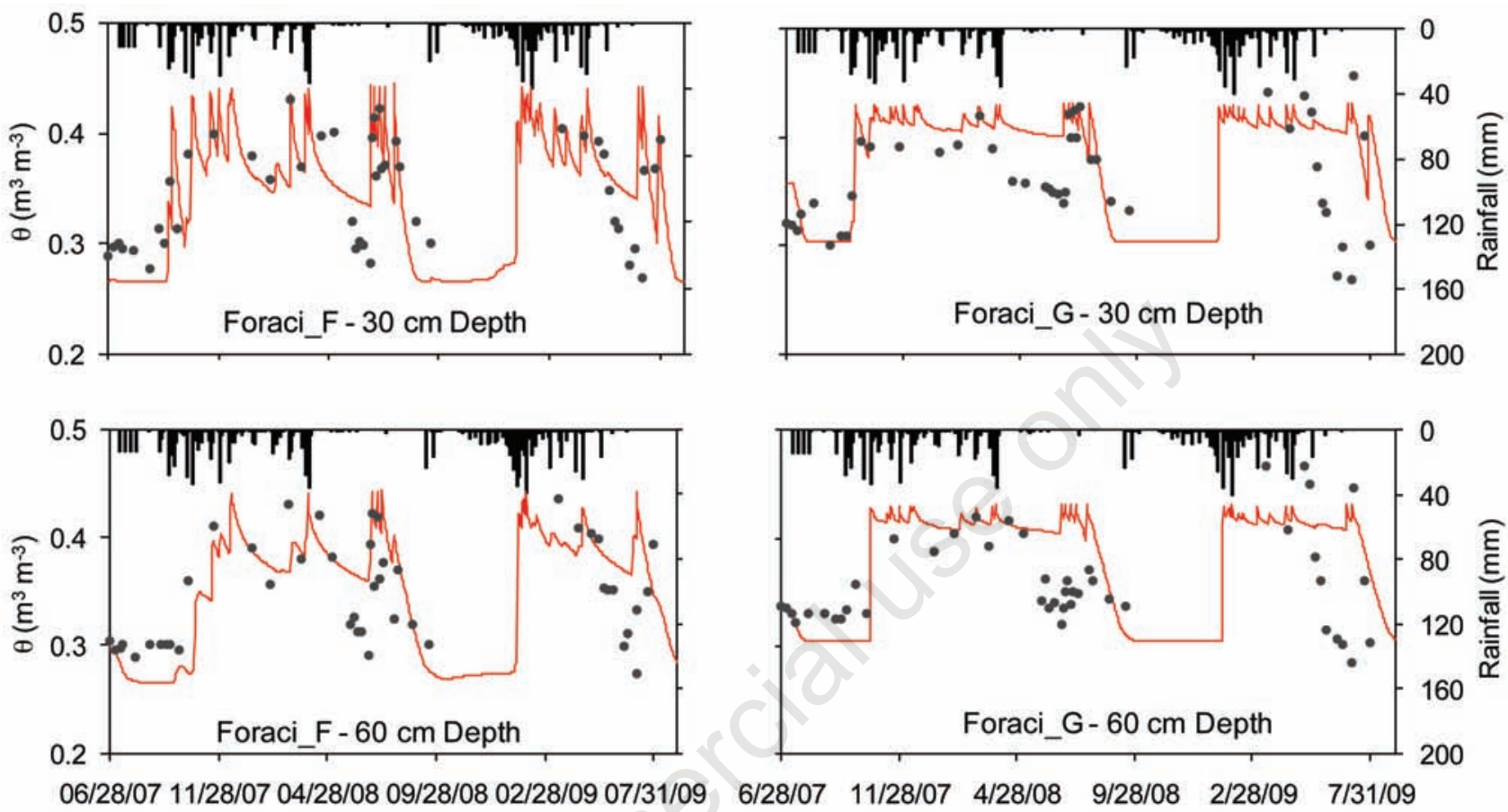

Figure 3. Water content measured and simulated by SWAP at 30 and at $60 \mathrm{~cm}$ in the two soil profiles.
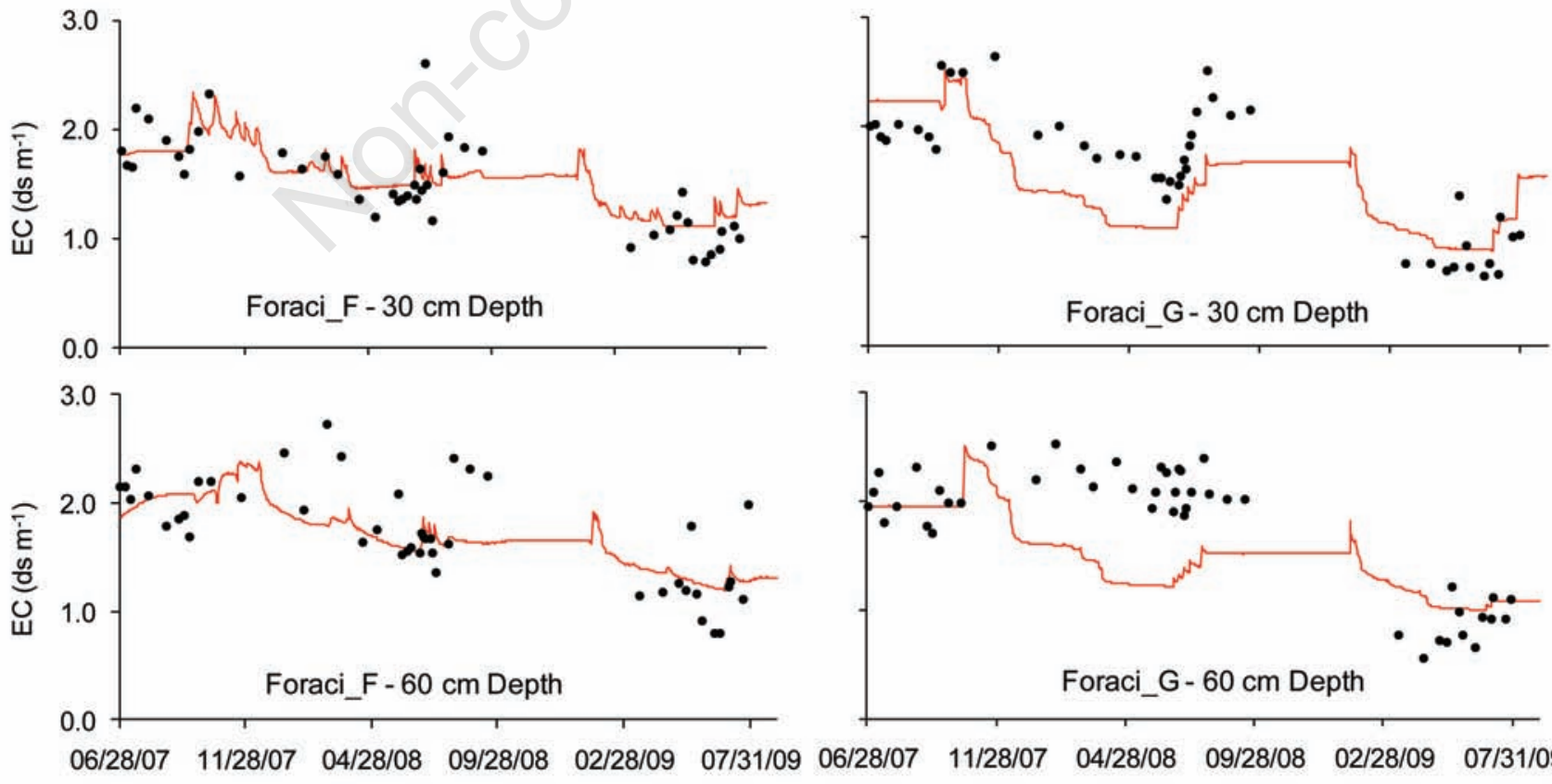

06/28/07 11/28/07 04/28/08 09/28/08

06/28/07 11/28/07 04/28/08 $09 / 28 / 08 \quad 02 / 28 / 09 \quad 07 / 31 / 09$

Figure 4. Agreement between simulated and measured $E C_{\text {sat }}$ for the two profiles at the depths of 30 and $60 \mathrm{~cm}$. 

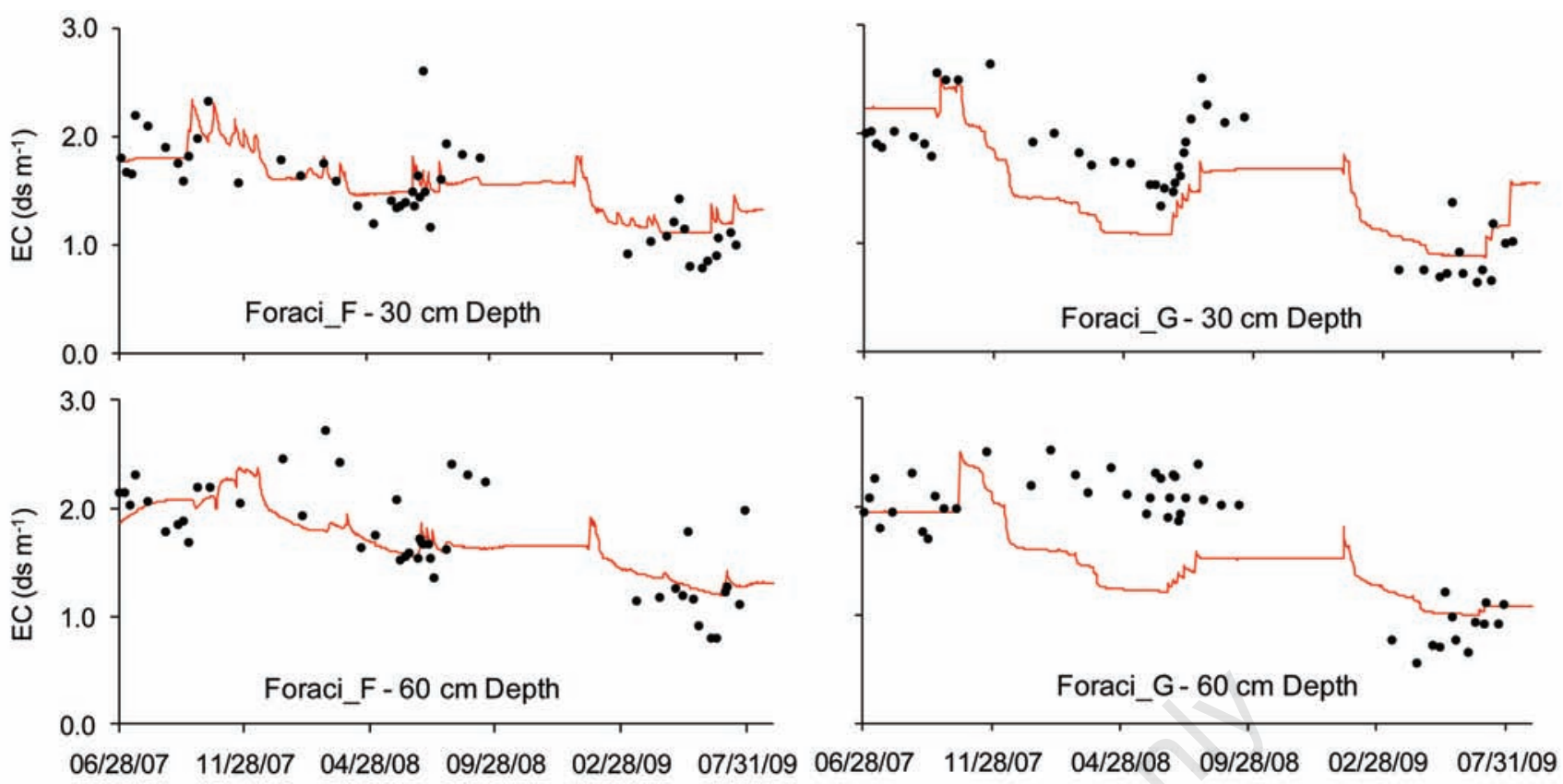

Figure 5. Temporal evolution of the crop water stress index (CWSI) for three representative years (2004 for the BASELINE, 2080 for B1 and A2) selected for each of the simulated scenarios (BASELINE, B1 and A2).

uted to the higher temperature observed in B1 compared to BASELINE. The trend observed in $\mathrm{B} 1$ can be observed again in $\mathrm{A} 2$, but in this case higher differences can be observed compared to BASELINE. The Figure also shows that three irrigation events (of about $50 \mathrm{~mm}$ each) were simulated by SWAP for all the three scenarios.

As it can be seen in Table 7, the crop cycle length (Cl) decreased of 16 and 27 days respectively in $\mathrm{B} 1$ and $\mathrm{A} 2$ compared to values obtained for the BASELINE scenario. As a consequence, compared to BASELINE, Tp showed a reduction of $6 \%$ in $\mathrm{B} 1$ and of $8 \%$ in $\mathrm{A} 2$. The same reductions can be observed for Ep. No significant differences were found in the Rainfall (R) considered by SWAP in B1 during the crop cycle. Instead, a reduction of $11 \%$ in $\mathrm{R}$ was found for A2. No significant differences were found in the irrigation amount (Ir) for B1 and A2, with an average value of about $150 \mathrm{~mm}$. An increase of about $11 \%$ was found in Ta for both $\mathrm{B} 1$ and A2. No significant differences were found in the actual soil evaporation (Ea) for both B1 and A2. The bottom flux (Bf) showed a significant reduction for $\mathrm{B} 1$ and $\mathrm{A} 2$ (33\% and $20 \%$,respectively). The CWSI showed a reduction of $32 \%$ and of $39 \%$ in $\mathrm{B} 1$ and $\mathrm{A} 2$, respectively, demonstrating a significant improvement in the crop water status. This significant improvement was confirmed by the increase of about $11 \%$ in the irrigation efficiency (IE) for both B1 and A2. Instead, the Er ratio remained constant and equal to about 0.28 for all the three scenarios. Considering that the main effect of the climatic scenarios $\mathrm{B} 1$ and $\mathrm{A} 2$ was to shorten the crop cycle, also advancing the phenological phases, SWAP was again applied to simulate an advance in the irrigation season of the same magnitude as the advance in the crop cycle (15 and $20 \mathrm{~d}$ for $\mathrm{B} 1$ and $\mathrm{A} 2$ respectively). The results obtained by these further simulations can be considered to provide a sort of adaptation strategy for the vineyard in terms of irrigation management that could be adopted by the farmers to deal with the impact of climate change on agriculture in the future.

The results, also reported in Table 7 and named $\mathrm{B} 1-\mathrm{AD}$ and $\mathrm{A} 2-\mathrm{AD}$, indicated that advancing the irrigation season did not determine significant changes in $\mathrm{Ta}, \mathrm{Ea}, \mathrm{Fb}, \mathrm{CWSI}$, IE and $\mathrm{Er}$ (comparison between between $\mathrm{B} 1$ and $\mathrm{B} 1-\mathrm{AD}$, and between $\mathrm{A} 2$ and $\mathrm{A} 2-\mathrm{Ad}$ ). This means that in the future farmers might modify the irrigation starting time(s) in order to avoid significant reduction in the crop productivity.

\section{Conclusions}

The SWAP model applied to two Sicilian profiles provided a satisfactory prediction of water content, $\theta$, as well as of electrical conductivity of soil saturated extract, $E C_{\text {sat }}$. These results confirmed that accurate simulation of water and solute transport can be obtained by the SWAP model if the soil hydraulic parameters have been accurately determined and represented. SWAP can be considered a reliable tool to be used to simulate management strategies and options. The main impact of climate change, as simulated by application of SWAP, was to shorten and advance the crop cycle. Since this effect counterbalanced the increase in the evaporative demand of the atmosphere predicted for the future by the climate change models, the irrigation requirement simulated by the model did not increase, remaining almost constant.

The simulations also showed that CWSI values tended to decrease in the future as an effect of climate change. This was the consequence of an increase in Ta and of a decrease in Tp due to crop cycle shortening. Should these simulated results reflect the reality for the future, farmers would probably advance the irrigation season of about 15-20 days as an adaptation strategy to climate change.

According to our results, application of this practice should make it possible not to determine negative effects on productivity. This information might be relevant not only for farmers but only for decision makers and irrigation networks. 


\section{References}

Ali R, Elliott RL, Ayars JE, Stevens EW, 2000. Soil salinity modelling over shallow water tables. I: Validation of LEACHC. J. Irrig. Drain. E.ASCE 126:223-233.

Brutsaert W, 1966. Probability laws for pore-size distribution. Soil Sci. 101:85-92

Crescimanno G, 2001. Irrigation practices affecting land degradation in Sicily. Ph.D Degree Diss., Wageningen University, The Netherlands.

Crescimanno G, Garofalo P, 2005. Application and evaluation of the SWAP model for simulating water and solute transport in a cracking clay soil. Soil Sci. Soc. Am. J. 69:1943-1954.

Crescimanno G, Garofalo P, 2006. Management scenarios optimizing irrigation with saline water in cracking clay soils. Soil Sci. Soc. Am. J. 70:1774-1787.

Crescimanno G, Marcum KB, 2009. Irrigation, salinization and desertification. Evolution of cropping systems as affected by climate change. (CLIMESC0). ISBN 978-88-548), Aracne.

Crescimanno G, Provenzano G, 1999. Soil shrinkage characteristic curve in clay soils: measurement and prediction. Soil Sci. Soc. Am. J. 63:25-32.

Doorenbos J., Kassam A.H. 1979. Yield response to water. Land and Water Development Div., FAO, Rome, Italy.

Gardner W.R., 1958. Some steady state solutions of the unsaturated moisture flow equation with application to evaporation from a water table. Soil Sci. 85:228-232.

Intergovernmental Panel on Climate Change, 2007. Summary for
Policymakers. In: Climate Change 2007: The Physical Science Basis. Contribution of Working Group I to the Fourth Assessment Report of the Intergovernmental Panel on Climate Change. Cambridge University Press, Cambridge, UK.

Pizzigalli C, Palatella L, Zampieri M, Lionello P, Miglietta MM, Paradisi $\mathrm{P}, 2012$. Dynamical and statistical downscaling of precipitation and temperature in a Mediterranean area. Ital. J. Agron. 7:e2.

Priestley CHB, Taylor RJ, 1972. On the assessment of surface heat flux and evaporation using large-scale parameters. Mon. Weather Rev. 100:81-82.

Rhoades JD, 1996. Salinity: electrical conductivity and total dissolved salts. In: D.L. Sparks, A.L. Page, P.A. Helmke, R.H. Loeppert, P.N. Soltanpour, M.A. Tabatabai, C.T. Johnston and M.E. Sumner (eds.) Methods of soil analysis. Part 3 - Chemical Methods. Book Series 5, American Society of Agronomy Publ., Madison, WI, USA, pp 417435.

Soil Survey Staff, 1999. Soil taxonomy: a basic system of soil classification for making and interpreting soil surveys, 2nd ed. US Department of Agriculture Soil Conservation Service Publ., Washington, DC, USA.

Southworth J, Randolph JC, Habeck M, Doering OC, Pfeifer RA, Rao DG, Johnston JJ, 2000. Consequences of future climate change and changing climate variability on maize yields in the Midwestern United States. Agr. Ecosyst. Environ. 82:139-158.

van Dam JC, Huygen J, Wesseling JG, Feddes RA, Kabat P, van Walsum PEV, Groenendijk P, van Diepen CA, 1997. Theory of SWAP version 2.0. DLO Winand Staring Centre Publ., Wageningen, The Netherlands.

Willmott CJ, 1981. On the validation of models. Phys. Geogr. 2:184-194. 